\title{
Article
}

\section{Sustainable Circular Business Model for Transparency and Uncertainty Reduction in Supply Chain Management}

\author{
Dawei Zhang ${ }^{1}$, Xiuli Huang ${ }^{1, *}$, Yunfeng Wen ${ }^{1,2}$, Pooja Trivedi ${ }^{3}$ and Shanmugan Joghee 4 \\ 1 School of Economics and Management, Guangdong University of Petrochemical \\ Technology, Maoming 525000, China; daweigongzuo@gdupt.cn (D.Z.); vinisen@gdupt.edu.cn (Y.W.) \\ 2 School of Education and Modern Languages, College of Arts and Sciences, Universiti Utara Malaysia, \\ Sintok 06010, Kedah, Malaysia \\ 3 Department of Business at Seneca College of Applied Arts and Technology, Seneca College, \\ Toronto, ON M2J 5G3, Canada; pooja.trivedi@senecacollege.ca \\ 4 School of Business, Skyline University College, Sharjah 1797, United Arab Emirates; \\ jshanmugan@skylineuniversity.ac.ae \\ * Correspondence: hxiuli@gdupt.edu.cn
}

check for updates

Citation: Zhang, D.; Huang, X.; Wen, Y.; Trivedi P.; Joghee, S. Sustainable Circular Business Model for Transparency and Uncertainty

Reduction in Supply Chain

Management. J. Theor. Appl. Electron. Commer. Res. 2021, 16, 959-975. https://doi.org/10.3390/ jtaer16040054

Academic Editor:

Hassan Qudrat-Ullah

Received: 24 December 2020

Accepted: 2 March 2021

Published: 8 March 2021

Publisher's Note: MDPI stays neutral with regard to jurisdictional claims in published maps and institutional affiliations.

Copyright: (c) 2021 by the authors. Licensee MDPI, Basel, Switzerland. This article is an open access article distributed under the terms and conditions of the Creative Commons Attribution (CC BY) license (https:/ / creativecommons.org/licenses/by/ $4.0 /)$.

\begin{abstract}
Circular Supply Chain Management (CSCM) incorporates the economy concept into supply chain concepts, which gives the supply chain sustainability domain an innovative and convincing viewpoint. The challenging factors in the circular economy are cooperation, trust, and transparency. Therefore, to achieve sustainable results, collaboration, and openness between organizations within networks and value chains are required. This paper explores the sustainability success using the Sustainable Circular Business Model (SCBM) to incorporate the principle at an operational level and suggest a structure for combining Circular Business Model (CBM) and CSCM for sustainable growth. The proposed structure shows how various circular business structures power the global supply chain in multiple loops. The circular business models differ according to the difficulty of the Circular Supply Chain (CSC) and the value proposition. Proposed SCBM shows that circular market and supply chain aid in reaching goals for sustainability has been discussed in this research.
\end{abstract}

Keywords: circular economy; supply chain management; circular business models; sustainable development

\section{Outline about the Research}

The traditional economies are built around a linear resource paradigm based upon the "take-make-dispose" pattern. After being used, the user disposes of the commodity, and much of the (sparse) resources have been wasted. In particular, the uncertainties of supply and higher resource prices are generated in the 21st Century due to a linear framework-based economy that leads to financial and economic volatility in individual businesses and prosperity worldwide [1]. Recently, policymakers have been involved in tackling these and other sustainability issues in a circular economy.

Sustainable development focused on meeting current needs while at the same time weakening the capacity of future generations to tackle the demands of them by identifying capital constraints and potential trade-offs among the economic, ecological, and societal goals [2]. The circular economy's philosophy, both textual and policy [3], is becoming essential guides for sustainable growth and is beginning to be accepted as of great importance in supporting industry for implementing a transformation in sustainability adoption.

The integration of consumption entry (CE) into supply chain management (SCM) can be scalable [4]. CE has become increasingly active and involved in the SCM framework. However, SCM analysis is beginning to develop ideas in the supply chain for the effectiveness of CE's mission and potential [5]. The study of the integration of CE into SCM is in its initial phase. Incorporating CE into a reality, and the realistic process for developing 
business models leads to the notion of circular business model (CBM), a term defining business model appropriate for CE [6].

The focus was on linking CBM and CSCM in several methods, including closed loops, shrinking loops, intense loops, expanding loops, and dematerializing loops. Theoretically, the most significant difference between conventional and circular economic business models lies in their value creation and distribution aspect, predominantly in the supply chain [7]. The word "Circular Supply Chain Management" (CSCM) encompasses the nature and collaboration of the supply chain to close, limit, strengthen, extend, and dematerialize resource loops. Although CSCM influences CBMs and the Circular economy's implementation, this research field remains untapped for a long time [8].

The notion of circular economy (CE) characterizes one of the most capable methods to establishing sustainable economic action for the future. A circular economy denotes a recreating model in which resource inputs and waste, emission, and energy outflow are reduced by decelerating, closing, and reduce material and energy loop. Supply chains are an important unit of activity concerning circular economy employment and success and will be the basis for driving desirable modification.

The present study aims to incorporate sustainable circular business model (SCBM), a framework to integrate CBM with CSCM to promote sustainable development towards the emergent visibility of CSCM and provide market insight on CBM. There are three case studies to address this goal as listed as follows:

- Case A-an office equipment maker,

- Case B-high-recycled aluminium sheet maker, and

- Case C-design of fashion accessories from fire pipe.

- The results show that a circular economy's theoretical implementation may reduce the demand for primary raw materials and related environmental influences.

The paper has five sections given as follows: First, the study's history is seen in $j$, and Section 3 offers applicable investigative methods. The outcome and explanation of the results are discussed in Section 4. The article ends with Section 5 regarding the conclusion and future work.

\section{Analysis of Conventional Methods}

A comprehensive literature overview is presented here, in which a formal, standardized interpretation of CSCM is elucidated, defined, and adequately differentiated from other theories of sustainability. In this section, the supply chain's existing sustainability principles are first listed, and their interaction with CE is recorded.

The literature on SCM [9] has given rise to sustainability in various academic literature reviews and discussions. Increasing unsustainability around the globe is due to patterns in growth, demand, and exchange. More renewable capital will be exhausted in the current usage rates shortly without increasing the production, refining, storage, consumption, recycling, and reuse of products [10]. A big hypothesis [11] that may contribute to this transition is the circular economy, which was gradually introduced as a good alternative to the prevalent linear business model (LBM).

Various concepts were developed and used interchangeably in SCM literature to illustrate sustainability values into the SCM [12], including moral supply chain, green supply chain, environment supply chains, and closed-loop supply chain [13]. While these ideas reflect varying degrees of integration into the supply chains of sustainability practices, none of them has expressly addressed loop philosophy, which is CE's central philosophy in SCM. There is a rather specific context in several recent papers for integrating CE in SCM [14]. Although this CE and SCM sustainability analysis is dispersed, some of the vital CE principles are strategically articulated, and others are based on SCM functions, such as architecture, procurement, development, etc.

Integrated CE-SCM implementation will reduce the need for new materials and improve disseminating goods across networks in the supply chain [15]. Nevertheless, incorporating CE into SCM is diverged based on the CE literature review [16]. Sustainable 
development at SCM centered on restoration solutions (repair, renovate, remanufacture, and recycling) while the idea of regeneration was not addressed in the sense of SCM sustainability [17]. Therefore, SCM's current sustainability principles need to be strengthened for the CSCM framework [18,19].

The circular economy's integration into SCM is known as circular supply chain management (CSCM). The outcome demonstrates ample scope and open doors for the development of circular supply chain management, which must be examined with improved quantitative modelling methods, highly industrialized optimization approaches, combined multi-criteria decision-making models, and capable algorithm [20].

Value chains have been mapped to envisage the relations and interfaces among the diverse phases and performers to comprehend these systems' difficulties and create informed decisions. These associations will be established within an adapted business and logistical structure framed in modern business model archetypes. Though dimensions connected to the business environment, like legislative, sectoral, and fiscal outlines, should be integrated [21].

The sustainability and CE models have signified separate academic literature streams, and there is a rising understanding that these two examples may have a mutually-constitutive association. Predominantly, the connection among the two concepts in the context of SC residues unmapped, which emphasizes this research. A structural equation modelling (SEM) method has been assumed to test the hypothesis derived. The validated structure has inferences for both industry and the academia due to its importance on the joint possessions of (a) the conversational capability of business performers to coherent a model change towards CSC, (b) the progression organizers encompassing activities and practices allow CSC [22].

Sustainability conversion is becoming progressively appropriate at manufacturing levels, particularly for energy and resource-intensive industries. In addition, the 4.0 industry-standard opens modern opportunities in terms of sustainable improvement. The consequences demonstrate the new company's sustainable value propositions, because of all three sustainability pillars: economy, society, and environments [23].

Sustainability problems on environmental, economic, and social viewpoints have drawn ecologists, governments, and environmentalists' attention. In this setting, the circular economy provides an opportunity to convert waste into resources, reduce production and consumption actions, and decrease carbon footprints, all simultaneously. This study offers an integrative outline for studying, scheming, and assessing the CSCM performance matrix [24].

With the importance and the need to integrate all the supply chain elements for the business model to maximize business model efficiency, SCBM has proposed to promote sustainable development. The proposed SCBM advances sustainability by implementing a circular economy's principle in supply chain processes and purposes. As in the circular economy theory, this refers to both manufactured goods and service goods. Concerning the study's operationalization, the implication of the circumstances in which the actors are inserted favored the case study's choice as a technical process. Recent improvements in sustainability have led administrations to integrate environmental, economic, and social factors in the supply chain. Sustainable SCM is designed to reduce material flows, both in consumption and production progression, decrease pollution, and waste generation during the supply chain.

\section{Sustainable Circular Business Model and Mathematical Analysis}

SCBM affiliate businesses from those intra and inter level to exploit the value of goods or resources. It provides an essential framework for leading supply chain management to increase the efficiency and profitability of capital. Hence, the negative environmental, neighborhood, and economic impacts are reduced. Value chains are required. This paper explores the sustainability success using the sustainable circular business model (SCBM) to incorporate the principle at an operational level and suggest a structure for combining 
circular business model (CBM) and CSCM for sustainable growth. The proposed structure shows how various circular business structures power the global supply chain in multiple loops. The circular business models differ according to the difficulty of the CSC and the value proposition.

As shown in Figure 1, CSCM is targeted at contributing to circular supply chains. Figure 1 compares the CSC shown in Figure 1a with the conventional linear supply chain and Figure $1 \mathrm{~b}$ closed-loop supply chain. A linear SC extracts environmental assets and needs to get rid of goods, packaging material, and waste from various supply chain phases. The undesirable objects are frequently stored in fields. The closed-loop supply chain increases ecological sustainability by returning a supplier's demand for products and packaging materials. The scope of the cost retrieval in the closed-loop supply chain is narrower since activities in the initial supplier (supply chain producer) are limited and secondary supply chains are not included, and the introduction of additional auxiliary channel members is involved, as shown in Figure 2.

A closed supply chain produces a considerable amount of waste because reusing/ recycling all discarded items in the same supply chain is hardly feasible. By partnering with similar sectors of industrial organizations or with different industrial sectors, a CSC may be used to extract profit out of waste. Ideally, CSC would achieve nil waste, as it has been built to preserve and recycle land continuously in terms of the agricultural and natural environment in which it is implemented. CSCs have two types of resource flow: the principal stream of resources and circular flow of funds, depicted in Figure 2. The forward movement of products characterizes the primary resource flow in the linear and closed-loop supply chain. Circular flow reflects the form of re-flow of products/components/energy, which is recycled, stored, reused, rehabilitated, recycled, etc. Domestic, agricultural, and commercial use is used to produce wastewater flows. Inflow and infiltration are processes used to characterize the runoff of the field and stormwater. Inflow reaches the system immediately because the penetration is the groundwater that enters from cracks and leaks.

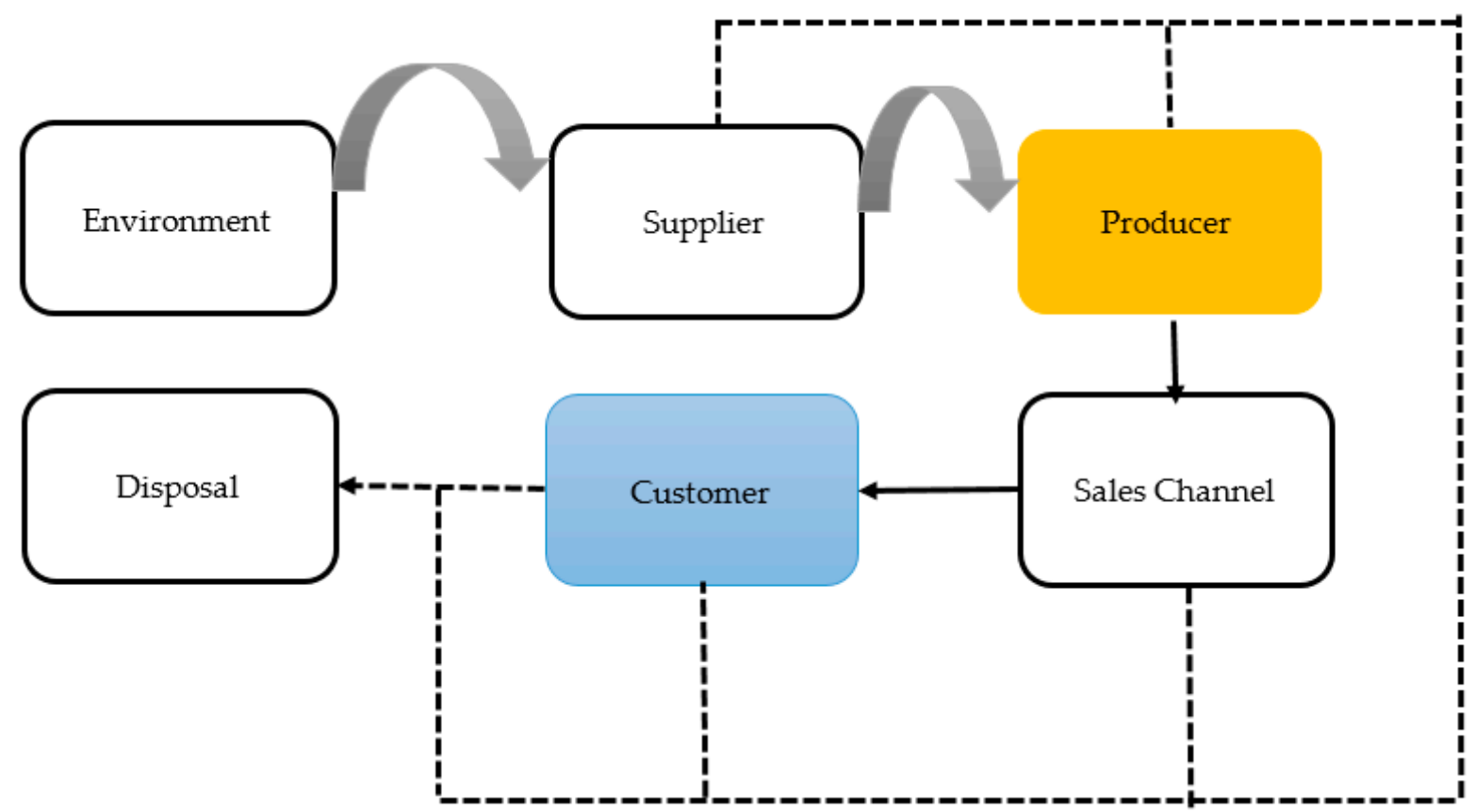

(a) Linear Model

Figure 1. Cont. 


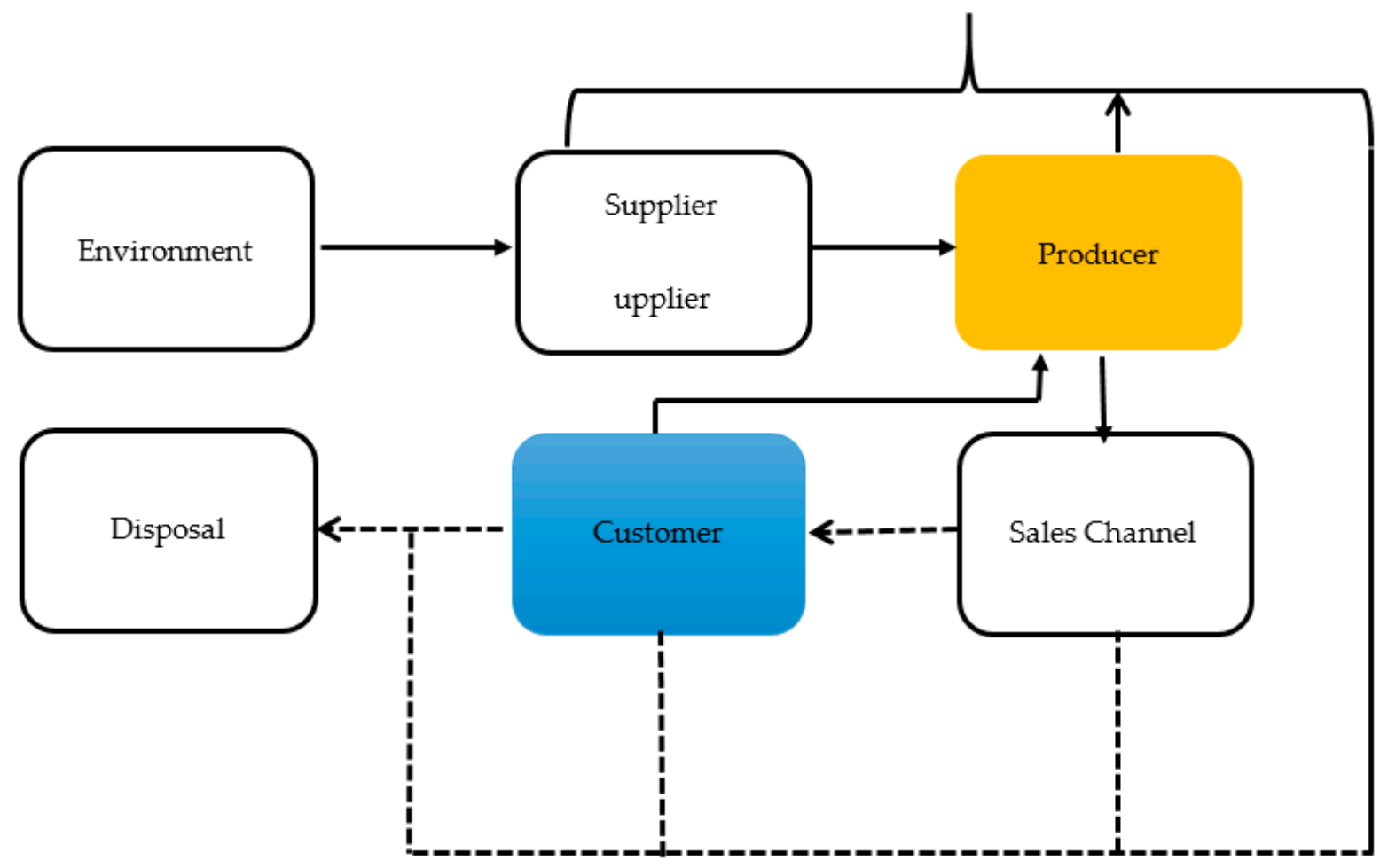

(b) Closed Loop model

Figure 1. Structure of different supply chain models.
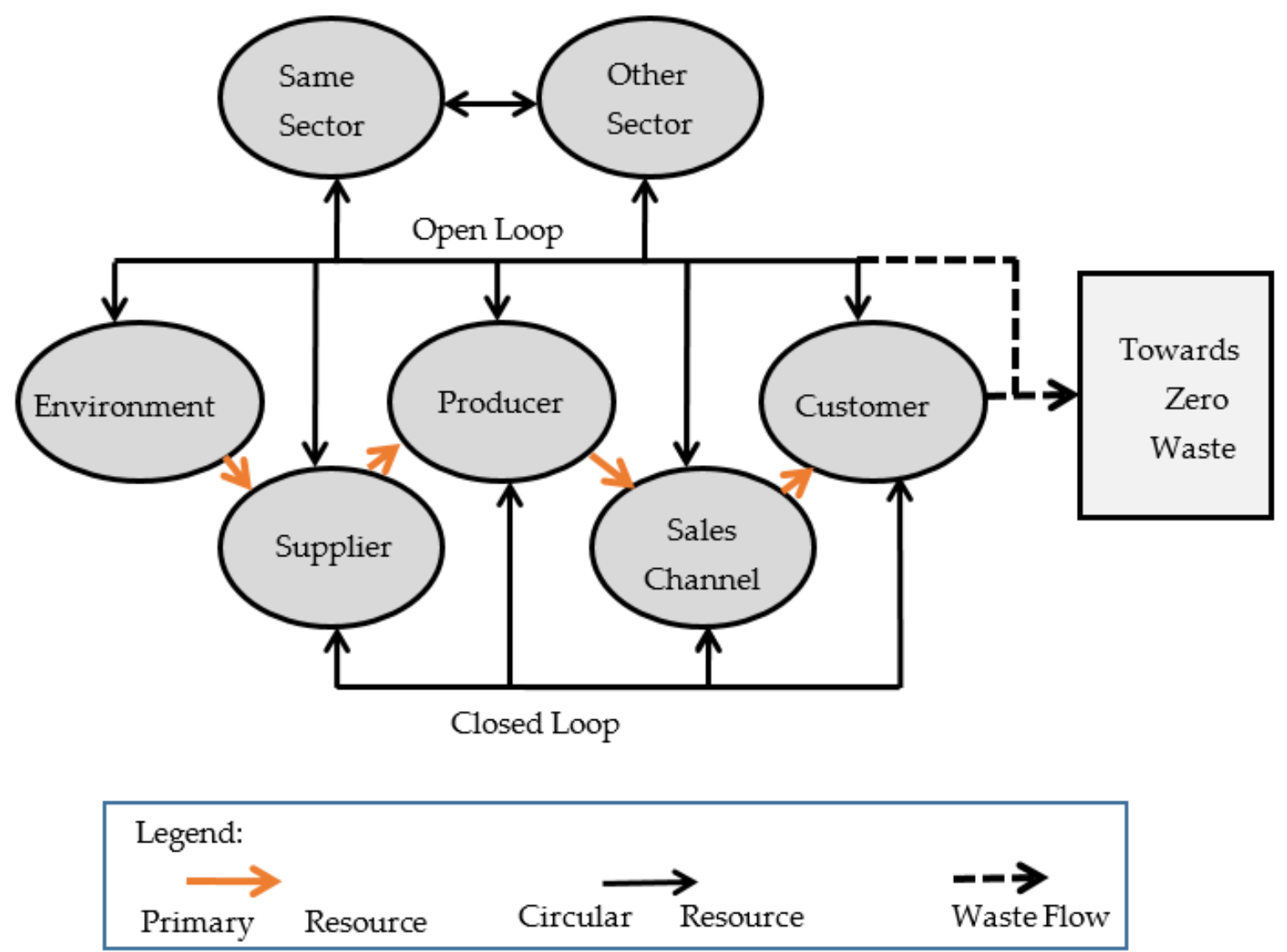

Figure 2. Circular Loop Model. 
SCBM performance has evaluated using detailed case studies. It often tailored for research into current trends, which is the situation with the present work, and offers a detailed explanation of particular implementations. The next phase was to pick the companies that were part of the study after the literature review, given the principal history. A specific selection criterion was established since the case studies involve theoretical learning rather than statistical research.

The critical evaluation benchmark is that the enterprise's operating structure would be associated with loop closure, slowing, intensification, reduction loops, and dematerialization. Three case studies were chosen to explore market prospects under the $\mathrm{CE}$ rationale to combine CBM with CSCM to promote sustainable growth (SCBM).

- Case A-an Office Equipment Supplier whose core concept includes remanufactured Office furniture using end products in an internal layout approach to delivering excellent goods.

- Case B-high-recycled aluminium sheet maker.

- Case C - design of fashion accessories from fire pipe.

Each chosen organization signifies a starting point for interpreting CE's elements and functions irrespective of specific industries and business models. The analysis of data was focused mainly on partially organized interviews with the company's primary informants. The major data have been gathered via direct observation of the procedures and semi-structured interviews with owners and managers. The consensus has been found between the players interviewed that circular economy practices compete with another precedence, and for financial explanations, are often unnoticed. In the data analysis, the interview and reporting biases were taken into account by corporate sustainability. Interview evidence has been augmented by written documentation and client databases to reduce this study constraint. Specific definitions of generic statements were often demanded during interviews. Due to their presence and general awareness about each client's business strategy, the primary informants were selected. The interviews contained questions on the interviewees' nature and attitudes in keeping with the SCBM of their respective businesses. In particular, the research questioned the (i) value proposition of the company as regards economic, environmental, and social benefit that the purpose of the business is to deliver; (ii) the design and distribution processes that concentrate on closing the commodity life cycle loop; and (iii) interest derived from each case study by the different stakeholders. The data collected is qualitatively evaluated according to the characteristics of sustainability.

\subsection{Analysis of SCBM}

\subsubsection{Risk Analysis}

For a constructive evaluation of a crucial business strategy that requires increased complexity and investment risk, SCBM raises significant challenges. This work describes corporate risk $(K)$ as a function of the likelihood in pre-investment and the amount of capital at risk. It means the probability of $V$ given as $P$, whereas the mixed investment probability is given by $(V-P)$ for the business model. $R$ denotes the amount of risked resources. It has been given as follows,

$$
K_{S C B M} \succ K_{L B M} \Leftrightarrow R_{C B M}\left(V-P_{C B M}\right) \succ R_{L B M}\left(I-P_{L B M}\right)
$$

In favor of inequalities, it can be shown that $P_{S C B M} \prec P_{C B M} \prec P_{L B M}$ for positive business model research of SCBM in contrast with CBM and LBM, it is more challenging to reduce uncertainty.

It has been illustrated in Figure 3 that $R_{S C B M} \succ R_{C B M} \succ R_{L B M}$ as the capital spent remains fragile before the business concept is tested in the industry, and for an SCBM, this will take longer. 


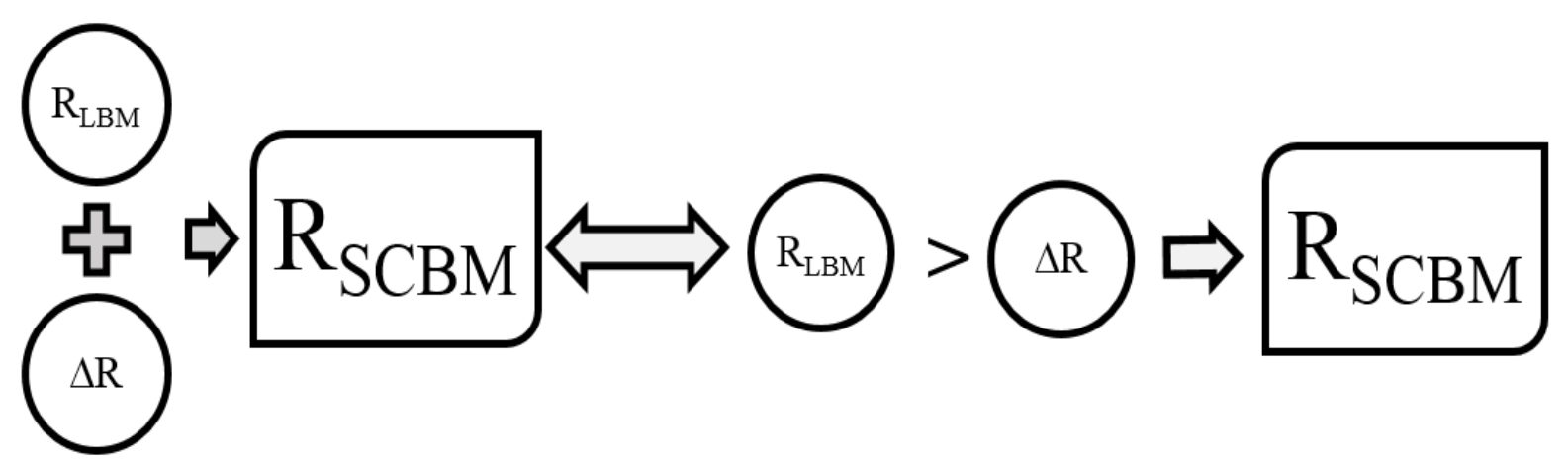

Figure 3. The relation between the magnitude of risked resources for sustainable circular business model (SCBM) and linear business model (LBM).

\subsubsection{Cost Analysis}

It is challenging for SCBM from a risk management perspective because the relevant market models have become more comprehensive in time. The hypothesis is analyzed based on the postulates for a shorter time to validate SCBM. That is because the underlying variables can shift over time to dictate cost/revenue. All of them are the company's quality at an individual rate of reconstruction in competition with rivals and suppliers. Consider, for example, the cost implications of a revolution in battery production under the SCBM framework. Although it can be built with some versatility, the implementation independence of a single-way LBM value chain is never established. Therefore, while an SCBM will offer other advantages, including lower manufacturing prices and minimized environmental impacts, it means a more significant challenge to test proactively the business model's hypotheses, which requires fewer postulates for deciding upon the business model (lower $P$ ). Thus it follows that

$$
P_{S C B M}<P_{L B M} \Leftrightarrow\left(I-P_{C B M}\right)>\left(I-P_{L B M}\right)
$$

The amounts of fixed costs $(F)$ plus variable costs $(p)$ multiplied by the validation time is the cumulative amount of capital spent before a business model is accepted as efficient. The time for validation $(T)$ can be determined in the number of deals made, or by contract time for continuous purchases. In the following equation, this is summed up:

$$
R_{p M}=F+p \times T
$$

In the first phase of an SCBM, it can be treated as a particular LBM case before any goods are delivered to the manufacturer. As long as the re-circulation does not require further spending, the amount of capital expended $(t=I)$ at this point is the same for SCBM and LBM. Hence, until some re-circulation decides the economic viability of the SCBM, there is an extra step to be taken to verify the SCBM. To clarify that, $t$ for SCBM is more reliable than for CBM and LBM. During a second cycle, operating costs for a CBM are generally much lower because the fundamental economic justification of a CBM is reduced product expenditures, as shown in Figure 4 based on the delay factor. 


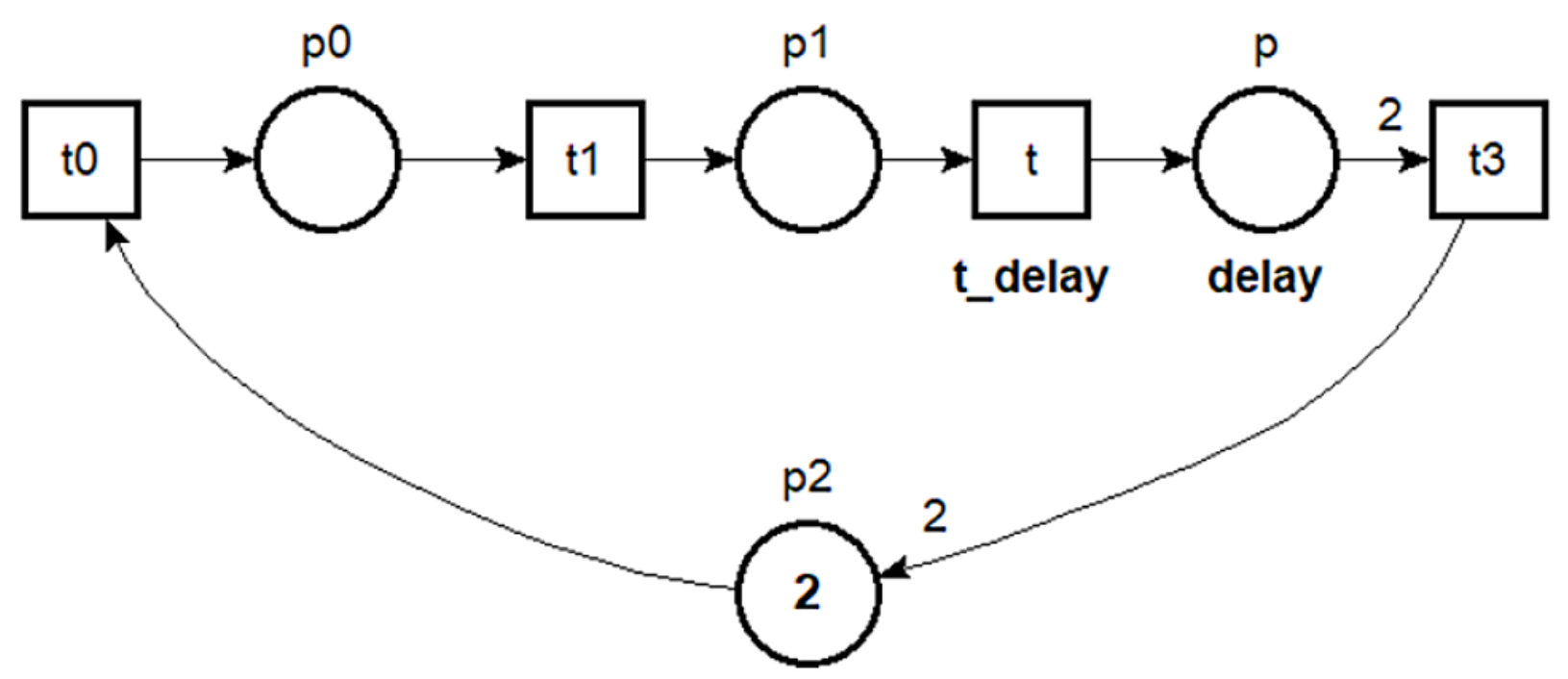

Figure 4. Resource analysis based on the time factor.

The magnitude of the resources that are spent at risk can be represented as

$$
\Delta R=p \times \Delta t
$$

where $\Delta t$ is defined as the new process needed to validate the SCBM. Since $K_{S C B M}$ consists of the first cycle $\left(R_{L B M}\right)$ plus the additional cycle $(\triangle R)$, the overall amount of capital spent is greater than for CBM and LBM to validate the business model. Thus,

$$
R_{S C B M}=R_{L B M}+\Delta R \Leftrightarrow R_{C B M}>R_{L B M}
$$

Though it is more complicated to achieve reliable performance for CBM than LBM using cost and revenue theory, SCBM aims at providing optimal performance with improved cooperation and reduced uncertainty.

\section{Simulation Analysis and Its Discussion Based on Case Study}

Proactive multiple stakeholder management refers primarily to the outcomes of the new SCBM. The pro-active handling of various partners is a significant factor for CSCM and CBM. A summary and value for each stakeholder are presented in Table 1.

It indicates that the companies, towards their stakeholders and other internal or external partners, have a constructive attitude. For example, Case A and Case C explicitly stated their desire to adhere to $\mathrm{CE}$ practices and enable collaborators and developments to make their circular activities feasible. Hence, Case B saw the potential by manufacturing high-quality aluminum sheets with a high proportion of the recycled content to reduce the reliance upon manufactured supplies with high carbon discharge that paves the way for robust investment in modern technologies. They partnered with customers in developing low-carbon components and aluminum applications, such as the market's active growth for low-carbon products. Case A faces challenges in creating a supply chain network that collects used office furniture at the end of life and integrates expertise and facilities to restore products. 
Table 1. Proposed SCBM taken by stakeholders for three cases A, B, and C.

\begin{tabular}{|c|c|c|c|}
\hline Stakeholder & Case A & Case B & Case C \\
\hline Investors & $\begin{array}{l}\text { Low cost, excellent progression, } \\
\text { and supportable trade }\end{array}$ & $\begin{array}{c}\text { Drop-in supply risk, long } \\
\text { term return }\end{array}$ & Corporate contentment \\
\hline Workforces & Chance to labour with a purpose & $\begin{array}{l}\text { Inspiration towards the goal of } \\
\text { achieving improved recycled } \\
\text { material levels in the commodity }\end{array}$ & $\begin{array}{l}\text { The operation for an industry } \\
\text { with a fair salary }\end{array}$ \\
\hline Customers & $\begin{array}{l}\text { Combination of quality and price } \\
\text { for wellness and productivity }\end{array}$ & $\begin{array}{l}\text { Partnership for the production of } \\
\text { low-carbon aluminum } \\
\text { components in high quality }\end{array}$ & $\begin{array}{l}\text { Long-term goods motivated } \\
\text { by design }\end{array}$ \\
\hline Suppliers & $\begin{array}{l}\text { Opportunity to market excess } \\
\text { waste (used as a cycle input) }\end{array}$ & $\begin{array}{l}\text { Production of equipment vendors } \\
\text { to respond to high recycled } \\
\text { content technological challenges }\end{array}$ & $\begin{array}{l}\text { Strong ties with resource } \\
\text { providers (such as the } \\
\text { Network of Firefighters) }\end{array}$ \\
\hline Society & $\begin{array}{l}\text { Local semi-experienced workers, } \\
\text { reduced supply risk, a running } \\
\text { circular business }\end{array}$ & $\begin{array}{l}\text { Ecological awareness, local } \\
\text { business participation in waste } \\
\text { management, low carbon } \\
\text { emission goods }\end{array}$ & Change to $\mathrm{CE}$ \\
\hline Environment & Less waste disposal on land & $\begin{array}{l}\text { Carbon removal in the } \\
\text { whole cycle }\end{array}$ & Less waste disposal on land \\
\hline Government & $\begin{array}{l}\text { Local semi-trained workers, } \\
\text { supply risk management, } \\
\text { working CE }\end{array}$ & $\begin{array}{l}\text { Preservation of domestic demand } \\
\text { for development }\end{array}$ & Tax benefits \\
\hline
\end{tabular}

The framework of SCBM shown in Figure 5 is recommended for Sustainable growth, $\mathrm{CE}, \mathrm{CSCM}$, and CBM integrated into action by way of the review and event studies. On the left, the structure suggested the connection as a CSC between a single organization, a certain $\mathrm{CBM}$, and its network of importance. In this context, the research confirms the previous claims regarding the CSCM's contribution to closing, limiting, and slowing down the loop, reinforcing this opinion, as discussed in Section 3. Empirical data from the findings of Table 1 (case studies) supports the network infrastructure's essential function and capacity to enable CBM to run. Initial reflections on the relationship between sustainable growth and $C E$ have been illustrated in previous research works. The present work investigates this connection by proposing SCBM to tackle CE's challenges and simultaneously provide sustainable growth, which provides empirical evidence for the relationships between these insights. In summary, the new SCBM system indicates a convergence in sustainable growth between CE and CBM. The overlapping field in Figure 5 is illustrated by the case studies that address the three survival-focused requirements on the closing, slowing, shrinking, intensifying, and dematerializing market paradigm.

Performance analysis has been carried out concerning three parameters: (i) magnitude of risked resources (R), (ii) cost, and (iii) validation time (T). 


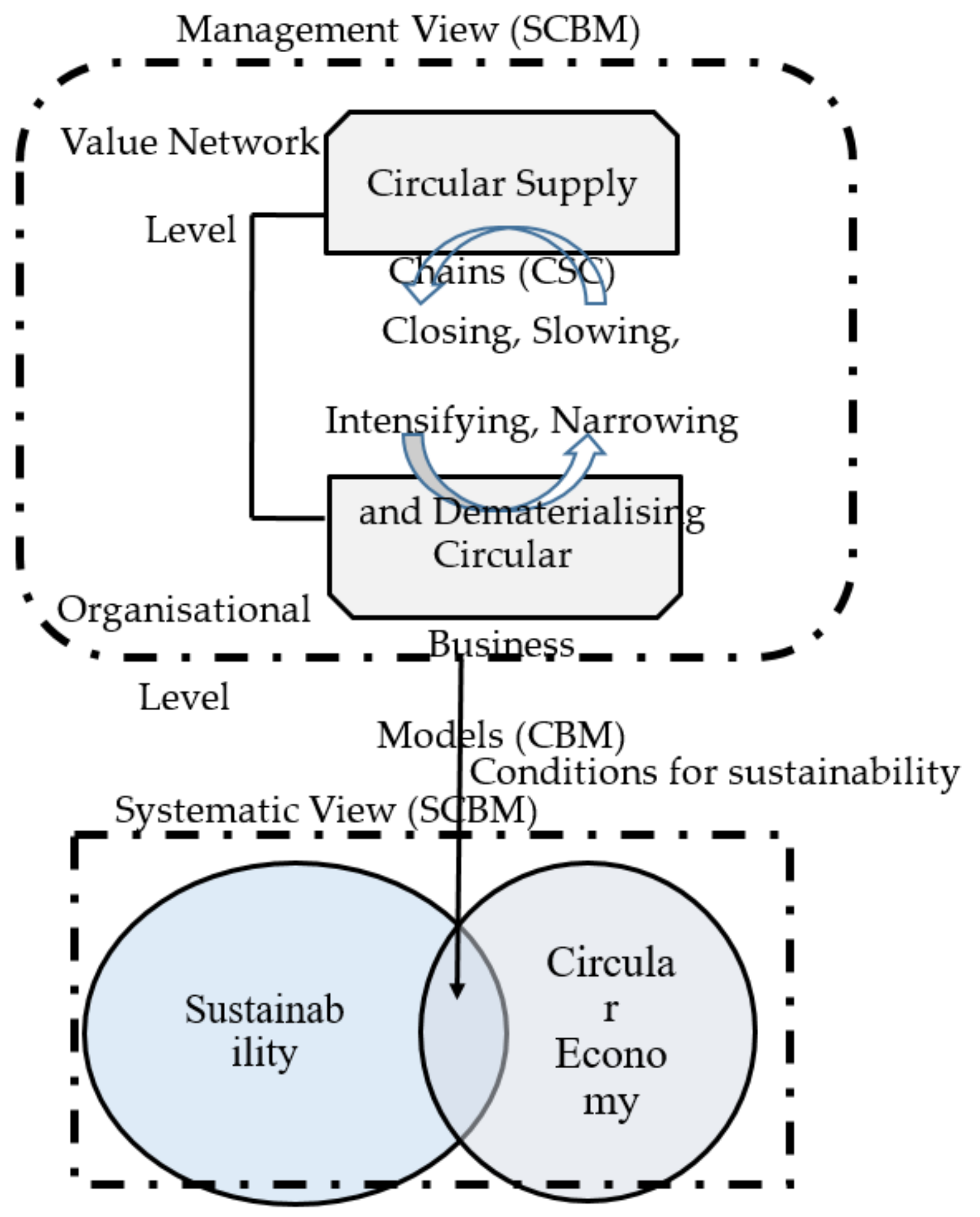

Figure 5. Proposed SCBM framework.

The following business models have been considered for comparison and are given as:

- $\quad$ Linear Business Model (LBM)

- Closed-Loop Supply Chain model (CLSC)

- Circular Business Model (CBM)

- Integrated CE-SCM model (CE-SCM)

- Proposed CBM with sustainability (SCBM) 
The constructive evaluation of core business model expectations causes more significant uncertainty, and subsequently, investment risk $[20,21]$ presented by CBM poses a severe obstacle. Figure 6 represents the number of risks involved in percentage for various business models. It can be inferred that CBM involves a high risk of $29.18 \%$ due to the reuse of resources with uncertainty. Instead, SCBM reduces the risk to $27.47 \%$ than CBM due to uncertainty reduction facilitated by cooperation and transparency between organizations and sustainability. CE-SCM provides a considerable per cent of risk (24.89\%) as they do not thrive to achieve sustainability, and uncertainties exist. CLSC provides a moderate risk per cent due to its closed-loop structure. LBM has the least risk of $4.72 \%$ as there is no reuse, and the process is straight forward.

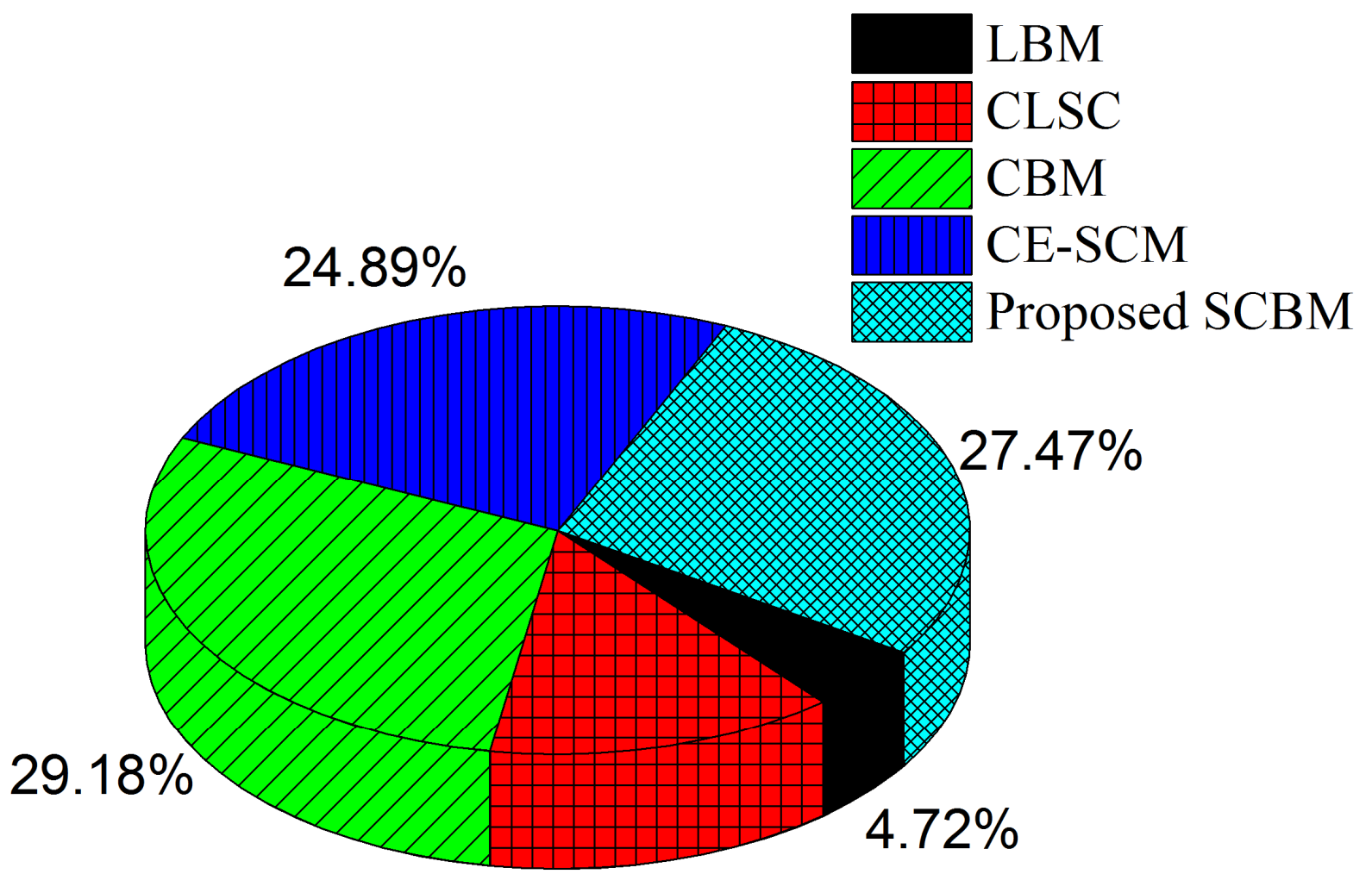

$13.73 \%$

Figure 6. Degree of risked resources (in \%) for various business models.

The total cost is the sum of fixed (F) and adaptable costs (B) multiplied by the validation time. The time for validation $(\mathrm{T})$ is determined by the number of deals made or by contract time for continuous purchases. Cost analysis varies with the number of times the product is successfully purchased after remanufacturing, denoted as the number of cycles, and depicted in Figure 7. It has been observed from the analysis that, in the first phase of SCBM, it can be treated as a particular LBM case before any goods are delivered to the manufacturer. Hence, until some re-circulation decides the economic viability of the SCBM, there is an extra step to be taken to verify the SCBM. To clarify that, T for SCBM is more durable than for CBM and LBM. During a second cycle, operating costs for an SCBM are generally much lower than LBM because the critical economic justification of SCBM is reduced product expenditures. The cost of CLSC and CE-SCM are higher than SCBM and CBM, particularly as the cycle increases. 


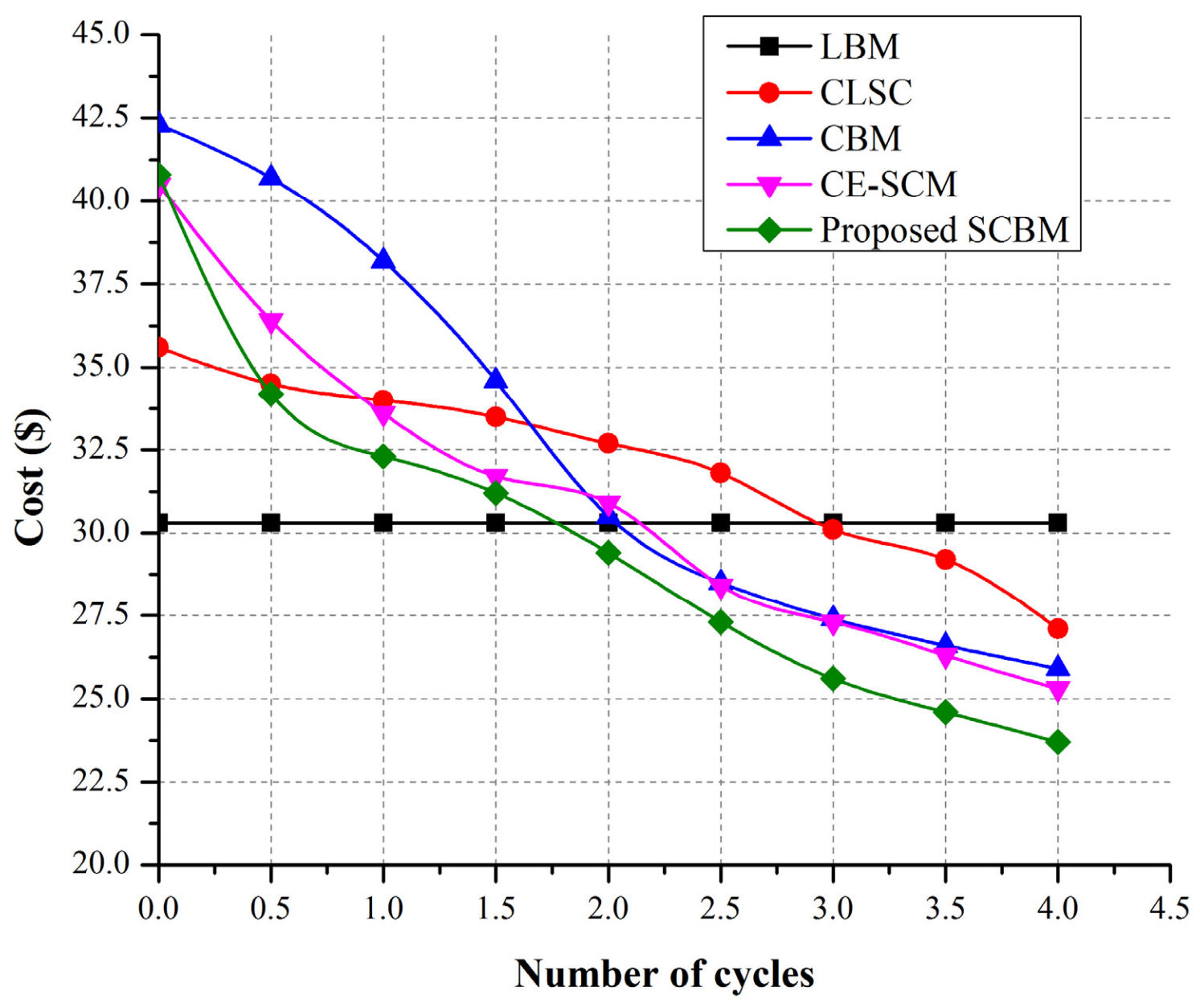

Figure 7. Cost analysis as a function of reuse cycles for different business models.

Figure 8 represents the validation time $(\mathrm{T})$ for different business models. The time for validation $(\mathrm{T})$ can be determined in the number of deals made or by contract time for continuous purchases. When some products are sold, LBM may be certified as validated, and $\mathrm{T}$ is small. Instead of SCBM, validation is considered as good recirculate products as sold successfully. Hence, SCBM has a high T. Until the financial viability of the CBM depends on some degree of re-circulation, a move to validate a CBM is required. It means the corroboration levels for CBM and CE-SCM are longer than for CLSC and LBM. 


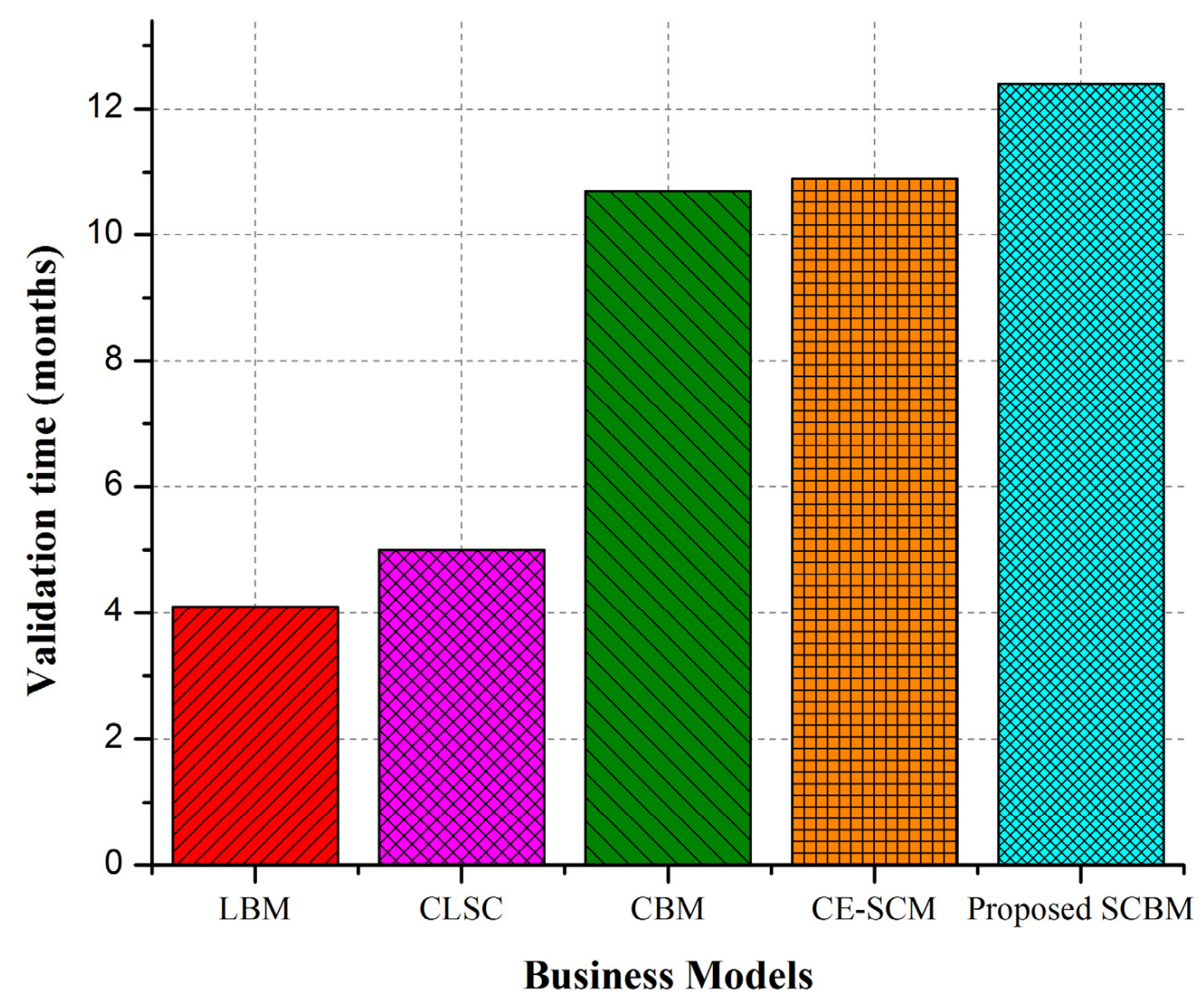

Figure 8. Validation time taken for various business models.

Figure 9 depicts the accuracy ratio obtained for an increasing number of questions asked for different stakeholders' cases during the interview for various business models. For LBM, the number of question sets does not affect the accuracy rate because there is no need to establish cooperation, or there is no need for reuse. Hence, LBM has a uniform accuracy ratio of $76.5 \%$. For all other business models, the accuracy ratio improves as the number of questions increased. Therefore, the higher the questions asked in the interview process, the better the clarity of business models, and hence accuracy improves. Proposed SCBM has the highest accuracy reaching $92 \%$ for 20 question sets. CLSC has reduced efficiency than CE-SCM and CBM, both of which have moderate accuracy. 


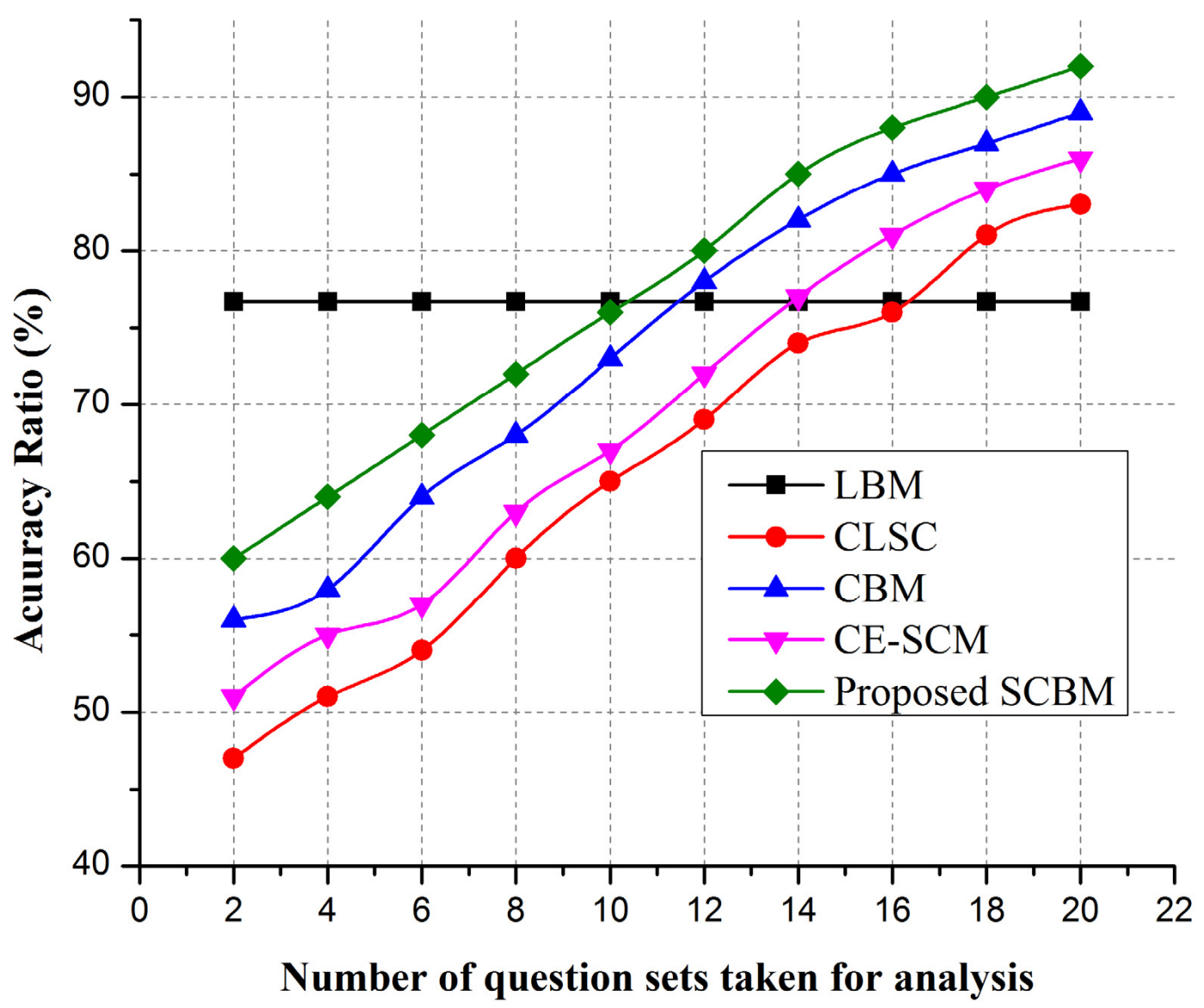

Figure 9. Accuracy ratio obtained for different question sets for various business models.

Figure 10 depicts the business models' overall performance, considering the total effect of risk, cost, time, and accuracy. It has been clearly shown that the proposed SCBM gave the best overall performance due to its reduced price and risk than CBM with better efficiency. CE-SCM provides degraded performance compared to CBM much better than CLSC and LBM. The overall production of business models has increased as the number of question sets increased for all the business models. Thus, the proposed SCBM outperforms all the existing business models and provides sustainable development for SCM. 


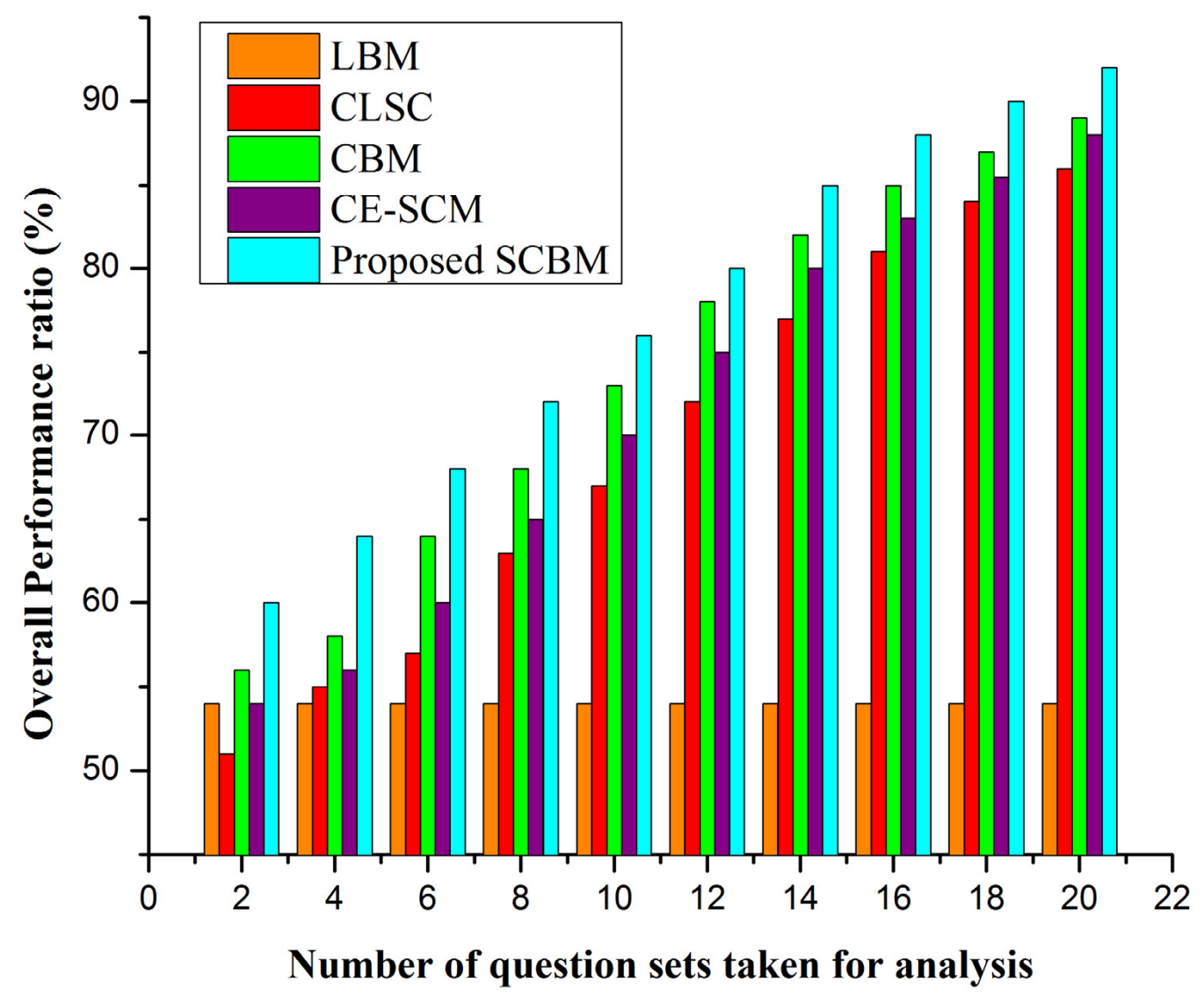

Figure 10. Overall performance ratio of various business models for several question sets. below:

As shown in Table 2, the advantages and disadvantages of these models are compared

Table 2. Advantages and Disadvantages of Business Models.

\begin{tabular}{|c|c|c|}
\hline Business Models & Advantages & Disadvantages \\
\hline LBM & Stimulate creativity & $\begin{array}{c}\text { Building a versatile business model may } \\
\text { be time-consuming }\end{array}$ \\
\hline CLSC & Guaranteeing more exact long-term planning & $\begin{array}{l}\text { It is problematic to model } \\
\text { inter-organizational systems }\end{array}$ \\
\hline CBM & $\begin{array}{l}\text { Provide an opportunity to generate new ideas, } \\
\text { new conceptions, decision }\end{array}$ & Model building requires special training \\
\hline CE-SCM & $\begin{array}{l}\text { Reducing the risk of changes in the } \\
\text { planning process }\end{array}$ & $\begin{array}{l}\text { Simulation outcome may be difficult } \\
\text { to interpret }\end{array}$ \\
\hline SCBM & $\begin{array}{l}\text { Help to understand the overall processes and } \\
\text { characteristics by graphical }\end{array}$ & $\begin{array}{l}\text { Different customers may perceive the } \\
\text { process differently. }\end{array}$ \\
\hline
\end{tabular}

\section{Research Summary and Future Perspective}

Thus the paper explores sustainability success using the sustainable circular business model (SCBM) to incorporate the principle at an operational level and suggest a structure for combining circular business model (CBM) and CSCM for sustainable growth. The proposed structure showed how various circular business structures power the global supply chain in multiple loops based on case studies. Simulation results and analysis for risk, cost, validation time, performance, and accuracy has been carried out. The proposed SCBM framework has reduced risk and cost than conventional CBM due to cooperation 
and product reuse with sustainability. The performance and accuracy of SCBM performed much better than other existing business models. Proposed SCBM shows that circular market and supply chain aid in reaching goals for sustainability. The numerical results show that the proposed SCBM model enhances the overall performance ratio of $95.6 \%$, accuracy ratio of $93.4 \%$, and cost of $\$ 25$ compared to other existing models.

A relatively small number of case studies were carried out in our research work, which could be extended. This significant research analysis may be carried out to complement the present interviews with other stakeholders from the supply chain. There are technical limitations to materials recycling and dissipative losses in any loops; therefore, material recycling vision may still be regarded as only theoretically probable in the distant future.

Author Contributions: Conceptualization, D.Z. and X.H.; methodology, X.H.; software, Y.W.; validation, P.T. and S.J.; formal analysis, D.Z.; investigation, X.H.; resources, Y.W.; data curation, P.T., S.J.; writing—original draft preparation, D.Z.; writing—review and editing, D.Z.; visualization, X.H.; supervision, Y.W.; project administration, Y.W.; funding acquisition, D.Z. and X.H. All authors have read and agreed to the published version of the manuscript.

Funding: This research was funded by the 13th Five-Year Plan Project for Education Science of Guangdong Province in 2020 (2020GXJK127); The 13th Five-Year Plan Project for Philosophy and Social Science of Guangdong Province in 2020 (GD20CYJ02); The 2018 Guangdong Provincial University Youth Innovation Talent Program (2018WQNCX109); The 2019 Guangdong Provincial University Youth Innovation Talent Program (2019WQNCX080) and the Projects of Talents Recruitment of GDUPT (2019rc030).

Institutional Review Board Statement: Not applicable.

Informed Consent Statement: Not applicable.

Data Availability Statement: The data presented in this study are available on request from the corresponding author. The data are not publicly available due to privacy and ethical restrictions.

Conflicts of Interest: The authors declare no conflict of interest.

\section{References}

1. Geissdoerfer, M.; Bocken, N.M.; Hultink, E.J. Design thinking to enhance the sustainable business modeling process-A workshop based on a value mapping process. J. Clean. Prod. 2016, 135, 1218-1232. [CrossRef]

2. Abdel-Basset, M.; Gunasekaran, M.; Mohamed, M.; Chilamkurti, N. A framework for risk assessment, management, and evaluation: Economic tool for quantifying risks in supply chain. Future Gener. Comput. Syst. 2019, 90, 489-502. [CrossRef]

3. Stewart, R.; Niero, M. Circular economy incorporate sustainability strategies: A review of corporate sustainability reports in the fast-moving consumer goods sector. Bus. Strategy Environ. 2018, 27, 1005-1022. [CrossRef]

4. Nasir MH, A.; Genovese, A.; Acquaye, A.A.; Koh SC, L.; Yamoah, F. Comparing linear and circular supply chains: A case study from the construction industry. Int. J. Prod. Econ. 2017, 183, 443-457. [CrossRef]

5. Abdel-Basset, M.; Manogaran, G.; Mohamed, M. Internet of Things IoT) and its impact on supply chain: A framework for building smart, secure and efficient systems. Future Gener. Comput. Syst. 2018, 86, 614-628. [CrossRef]

6. Bocken, N.M.; De Pauw, I.; Bakker, C.; van der Grinten, B. Product design and business model strategies for a circular economy. J. Ind. Prod. Eng. 2016, 33, 308-320. [CrossRef]

7. Kazancoglu, Y.; Kazancoglu, I.; Sagnak, M. A new holistic conceptual framework for green supply chain management performance assessment based on the circular economy. J. Clean. Prod. 2018, 195, 1282-1299. [CrossRef]

8. Gao, Q.; Guo, S.; Liu, X.; Manogaran, G.; Chilamkurti, N.; Kadry, S. Simulation analysis of supply chain risk management system based on IoT information platform. Enterp. Inf. Syst. 2019, 1-25. [CrossRef]

9. Morali, O.; Searcy, C. A review of sustainable supply chain management practices in Canada. J. Bus. Ethics 2013, 117, 635-658. [CrossRef]

10. Hazen, B.T.; Mollenkopf, D.A.; Wang, Y. Remanufacturing for the circular economy: An examination of consumer switching behavior. Bus. Strategy Environ. 2017, 26, 451-464. [CrossRef]

11. Ghisellini, P.; Cialani, C.; Ulgiati, S. A review on circular economy: The expected transition to a balanced interplay of environmental and economic systems. J. Clean. Prod. 2016, 114, 11-32. [CrossRef]

12. Gurtu, A.; Searcy, C.; Jaber, M.Y. An analysis of keywords used in the literature on green supply chain management. Manag. Res. Rev. 2015, 38, 166-194. [CrossRef]

13. Ahi, P.; Searcy, C. An analysis of metrics used to measure performance in green and sustainable supply chains. J. Clean. Prod. 2015, 86, 360-377. [CrossRef] 
14. Batista, L.; Bourlakis, M.; Smart, P.; Maull, R. In search of a circular supply chain archetype-a content-analysis-based literature review. Prod. Plan. Control 2018, 29, 438-451. [CrossRef]

15. Genovese, A.; Acquaye, A.A.; Figueroa, A.; Koh, S.L. Sustainable supply chain management and the transition towards a circular economy: Evidence and some applications. Omega 2017, 66, 344-357. [CrossRef]

16. Aminoff, A.; Kettunen, O. Sustainable supply chain management in a circular economy-towards supply circles. In Proceedings of the International Conference on Sustainable Design and Manufacturing, Crete, Greece, 4-6 April 2016; Springer: Cham, Chania, 2016; pp. 61-72.

17. Farooque, M.; Zhang, A.; Thurer, M.; Qu, T.; Huisingh, D. Circular supply chain management: A definition and structured literature review. J. Clean. Prod. 2019, 228, 882-900. [CrossRef]

18. Jabłoński, A.; Jabłoński, M. New Economy Business Models in the Concepts of Big Data, the Sharing Economy and the Circular Economy. In Social Business Models in the Digital Economy; Palgrave Macmillan England: London Borough of Camden, UK, 2020; pp. 51-88.

19. De Angelis, R.; Feola, R. Circular business models in biological cycles: The case of an Italian spin-off. J. Clean. Prod. 2020, 247, 119603. [CrossRef]

20. Lahane, S.; Kant, R.; Shankar, R. Circular supply chain management: A state-of-art review and future opportunities. J. Clean. Prod. 2020, 258, 120859. [CrossRef]

21. González-Sánchez, R.; Settembre-Blundo, D.; Ferrari, A.M.; García-Muiña, F.E. Main dimensions in the building of the circular supply chain: A literature review. Sustainability 2020, 12, 2459. [CrossRef]

22. Hussain, M.; Malik, M. Organizational enablers for circular economy in the context of sustainable supply chain management. J. Clean. Prod. 2020, 256, 120375. [CrossRef]

23. García-Muiña, F.E.; Medina-Salgado, M.S.; Ferrari, A.M.; Cucchi, M. Sustainability transition in industry 4.0 and smart manufacturing with the triple-layered business model canvas. Sustainability 2020, 12, 2364.

24. Jain, S.; Jain, N.K.; Metri, B. Strategic framework towards measuring a circular supply chain management. Benchmarking Int. J. 2018, 25, 3238-3252. [CrossRef] 